\title{
Prevalence of Eating Disorders: Its Relationship with Alexithymia and Mental Complaints
}

\author{
Yeme Bozukluklarının Yaygınlığı: Aleksitimi ve Ruhsal \\ Yakınmalarla İlişkisi
}

\author{
Hatice Harmanc1 ${ }^{1}$, Seher Akdeniz ${ }^{2}$, Zeynep Gültekin Ahçı ${ }^{3}$
}

\begin{abstract}
:
The aim of this study is to investigate the prevalence of eating disorders (ED) among university students who are considered to be at high risk in terms of ED, where productivity in life is more important, and also to examine alexithymia and other mental symptoms that ED may be associated with. This is a descriptive relational study. Four hundred twenty one university students with appropriate participation conditions were included in the research. Sociodemographic information form, Eating Attitude Test (EAT-40), Toronto Alexithymia Scale (TAS-20) and Symptom Check List (SCL-90-R) scales were applied to the participants. The data were evaluated with the SPSS 25.0 statistics program. Participants with an average age of 19,82 $\pm 10,11 ; 58,2 \%$ were women, 97\% were single, $71,7 \%$ were living with their families. Eating disorder prevalence was $20,9 \%$ and it was found that eating attitude disorder was more common among women. Among individuals with eating disorders, alexithymia total score and two alexithymia subscale scores, difficulty recognizing emotions and expressive thought, were significantly higher. At the same time, the anxiety, hostile attitude and psychoticism score indexes of the individuals with ED were found to be significantly higher. It is very important in terms of social functionality to recognize ED, whose incidence is gradually increasing, and to direct patients to effective treatment. Alexithymic complaints can cause ED or increase the severity of the existing disorder. Comorbidity of mental complaints with ED is common. A detailed evaluation of the factors that cause ED and affect symptom severity will increase treatment success.
\end{abstract}

Keywords: Eating Disorders, Alexithymia, Mental Symptoms

${ }^{1}$ Ass. Prof. Dr., KTO Karatay University, Psychology Department, Karatay-Konya-Turkey, Orcid İd: https://orcid.org/00000003-4064-5391

${ }^{2}$ Ass. Prof. Dr., KTO Karatay University, Psychology Department, Karatay-Konya-Turkey, Orcid İd: https://orcid.org/00000002-2282-9165

${ }^{3}$ Ass. Prof. Dr., KTO Karatay University, Psychology Department, Karatay-Konya-Turkey, Orcid İd: https://orcid.org/00000002-2383-7167

Address of Correspondence/Yazışma Adresi: KTO Karatay University, Faculty of Social and Human Sciences, Department of Psychology, Karatay-Konya-Turkey, E-mail: hatice.harmanci@karatay.edu.tr

Date of Received/Geliş Tarihi: 23.09.2020, Date of Revision/Düzeltme Tarihi: 19.12.2020, Date of Acceptance/Kabul Tarihi: 27.12.2020, Date of Online Publication/Çevirimiçi Yayın Tarihi: 12.01.2021

Citing/Referans Gösterimi: Harmancı, H., Akdeniz, S., Ahçı Gültekin, Z. (2021). Prevalence of Eating Disorders: Its Relationship with Alexithymia and Mental Complaints., Cyprus Turkish Journal of Psychiatry \& Psychology, 3(1): 30-36

(C) 2020 The Author(s). Published by Cyprus Mental Health Institute / Cyprus Turkish Journal of Psychiatry and Psychology (www.ktppdergisi.com). This article is an open access article distributed under the terms and conditions of the Creative Commons Attribution 4.0 license which permits use, sharing, adaptation, distribution and reproduction in any medium or format, provided the original work is properly cited and is not used for commercial purposes. http://creativecommons.org/licenses/by/4.0/ 


\section{Özet:}

Çalışmanın amacı, yaşamsal üretkenliğin daha çok önemsendiği ve yeme bozuklukları (YB) açısından yüksek riskli olarak değerlendirilen üniversite öğrencilerinde YB yaygınlığını araştırmak, aynı zamanda YB'nin ilişkili olabileceği aleksitimi ve diğer ruhsal belirtileri incelemektir. Araştırma ilişkisel tarama modelinde ve tanımlayıcı bir çalışma olarak planlanmıştır. Çalışmaya katılma şartlarına uygun 421 üniversite öğrencisi, gönüllülük usulüne göre araştırmaya dahil edilmiştir. Katılımcılara araştırmacılar tarafından oluşturulmuş sosyodemografik bilgi formu, Yeme Tutumu Testi (YTT-40), Toronto Aleksitimi Ölçeği (TAÖ-20) ve Belirti Tarama Listesi (SCL-90-R) ölçekleri uygulanmıștır. Elde edilen veriler SPSS 25.0 istatistik programı ile değerlendirilmiștir. Yaş ortalamas1 19,82 \pm 10,11olan katılımciların; \%58,2'si kadın, \%97'si bekar, \%71,7'i ailesi ile birlikte yaşamaktadır. Yeme bozukluğu yaygınlığı \%20,9 olarak belirlenmiş, kadınlarda yeme tutumu bozukluğunun daha fazla olduğu tespit edilmiştir. Yeme bozukluğu olan bireylerde aleksitimi toplam puanı ile aleksitimi alt ölçeklerinden; duyguları tanıma zorluğu ve dışa vuruk düşünce puanları anlamlı düzeyde yüksektir. Aynı zamanda yeme tutumu bozulan bireylerin kaygı, düşmanca tutum ve psikotizm puan indeksleri de anlamlı yüksek bulunmuştur. Yeme bozuklukları sık görülen ruhsal hastalıklardandır. Aleksitimik yakınmalar YB'ye sebep olabilmekte veya var olan bozukluğun şiddetini artırabilmektedir. Ruhsal yakınmaların YB ile birlikteliği sıktır. Yeme bozukluklarına sebep olan ve belirti şiddetini etkileyen faktörlerin ayrıntılı olarak değerlendirilmesi tedavi başarısını artıracaktır.

Anahtar Kelimeler: Yeme Bozuklukları, Aleksitimi, Ruhsal Belirtiler

\section{Giriş}

Yeme bozuklukları (YB) yaşam kalitesini bozduğu, beraberinde fiziksel ve ruhsal hastalıklara sebep olabildiği ve hatta ölümle sonuçlanabildiği için Dünya Sağlık Örgütü tarafından 'önemli tıbbi durum' olarak kabul edilmiştir (Andersen ve Yager, 2007). Ruhsal Bozuklukların Tanımsal ve Sayımsal El Kitabı - 5 (DSM5) YB'yi; anoreksiya nervoza, bulimia nervoza, tıkanırcasına yeme bozukluğu, pika, geviş getirme bozukluğu, kaçınıcı/kısıtlı besin alımı bozukluğu, diğer belirlenmiş beslenme ve yeme bozuklukları ve belirlenmemiş beslenme ve yeme bozuklukları şeklinde 8 farklı başlık altında tanımlamaktadır (Köroğlu, 2015).

Yeme bozuklukları diğer psikiyatrik hastalıklara kıyasla daha az çalışılmış ve daha çok bilinmezi barındıran bir alandır. Hastalık sıklığının, alt tiplerine göre değişmekle birlikte $\% 0,9$ - 3,5 olduğu bildirilmiștir, ancak yapılan son araştırmalar oranların giderek arttığını göstermektedir (Öztürk ve Uluşahin, 2018). Yeme bozukluklarındaki muayene bulguları homojen bir dağılım göstermez, toplumlarda ve bireylerde farklı klinik belirtilerle karşımıza çıkabilir. Aynı zamanda YB'nin neden kaynaklandığı ve nasıl oluştuğu da açık değildir. Genetik, biyolojik, sosyal, kültürel, ruhsal ve ekonomik kaynaklı risk faktörlerinin patolojinin oluşmasında etkili olduğu kabul edilir (Ricciardelli, McCabe ve Holt, 2003). Etyolojiyi açıklamaya yönelik yapılan çalışmalarda, ruhsal kökenli sebepler arasında tartışılan önemli faktörlerden bir tanesi de aleksitimidir (Andersen ve Yager, 2007).

Aleksitimi ilk defa 1970'lerde psikosomatik yakınmaları olan hastaların ruhsal belirtilerini tarif etmek için kullanılmış bir kavramdır. Bu dönemde aleksitimi tanımı duygularını ifade edemeyip, şikayetlerini somutlaştırarak somatik yakınmalara dönüştüren kişiler için kullanılmıştır (Sifneos, 1973). Artan çalışmalarla birlikte sorunun sadece psikosomatik bileşenlerle ilgili olmadığ tespit edilmiş ve duygusal sağırlık tanımı kullanılmıştır. Bu tanımlamaya göre aleksitimik bireyler hem kendilerinin hem de diğer insanların duygularını tanıyamamakta ve hissettiklerini de uygun ifade edememektedirler (Taylor, 2000). Bir kişilik özelliği olarak kabul edilen aleksitiminin genetik, gelişimsel ve sosyal yaşam gibi pek çok faktöre bağlı geliştiği düşünülmektedir (Duddu, Isaac ve Chaturverdi, 2003). Aleksitimi kendi başına psikiyatrik bir tanı değildir ancak yol açtığ olumsuzluklar sebebiyle yeme bozuklukları, bağımlılıklar, duygudurum bozuklukları, kaygı bozuklukları gibi ruhsal hastalıkların oluşmasını kolaylaştırmakta aynı zamanda bu hastalıklarda belirti şiddetini ve tedaviye direnci artırabilmektedir (Bayraktutan, 2014).

Yeme bozukluklarında, diğer ruhsal hastalıkların birlikteliğine sık rastlanır (Andersen ve Yager, 2007). Kountza ve arkadaşlarının çalışmasında anoreksiya nervozaya en sık eşlik eden ruhsal bozuklukların majör depresif bozukluk, kişilik bozukluğu ve obsesif kompulsif bozukluk olduğu gösterilmiştir (Kountza, Garyfallos ve Ploumpidis, 2018). Depresif bozukların klinik belirtileri içinde yemeyle ilgili bozulmaların varlığ ve YB'de duygudurumun çoğunlukla depresif olması, iki hastalık grubu arasında önemi etkileşim varlığını göstermektedir. Depresyonun, YB'de temel belirti olduğunu bildiren araştırmalar da bulunmaktadır (Holtkamp, Muller ve Heussen, 2005). Kilo değişimi ve besinlerle ilgili yoğun kaygının yaşandığı YB'ye kaygı bozuklukları da sıklıkla eşlik eder (Kaye, Bulik ve Thornton, 2004; Godart, Flament ve Perdereau, 2002)

Gelişimsel kuramlara göre erken yetişkinlik dönemi yaşam içi değişkenlerin daha fazla olduğu bir karar verme dönemidir. Kariyer ve meslek seçimi, üniversite öğrenciliği, çekirdek aileden ilk defa uzaklaşma, yeni bir düzen ile kendi yaşamını yönetme gibi pek çok değişimi içerir ve stresle baş etme yeteneği oldukça önemlidir. Bu dönemdeki zorlanmalar, duygusal yeme atakları ve diğer YB'nin gelişmesi açısından risklidir (Schulte, 2016). Literatüre göre YB'nin en yaygın görüldüğü yaş grubu olan erken yetişkinlikte, bozuklukları erken fark edebilmek tedavinin seyri açısından oldukça önemlidir (Andersen ve Yager, 2007). Yeme bozuklukları ile birlikte eklenecek fiziksel ve diğer ruhsal yakınmalar göz önüne alınırsa, erken ve etkili tedavinin hem bireysel işlevsellik hem de toplumsal kazanç açısından oldukça önemli olduğu görülmektedir. $\mathrm{Bu}$ araştırmanın temel amacı, risk grubu olarak değerlendirilen üniversite 
öğrencilerinde YB yaygınlığını ve YB'nin ilişkili olduğu düşünülen aleksitimi öncelikli olmak üzere diğer ruhsal değişkenleri tespit edebilmektir. Çalışmanın amacı doğrultusunda cevap aranacak temel problem soruları aşağıdaki gibidir.

1) Üniversite öğrencileri arasında YB yaygınlığ düzeyi nedir?

2) Yeme bozuklukluğu olan bireylerde aleksitimi düzeyi nedir?

3) Aleksitimi ile YB arasında ilişki var mıdır?

4) Yeme bozukluklarıyla birlikteliği daha sı olan ruhsal yakınmalar nelerdir?

\section{Yöntem ve Gereçler}

\section{Çalışma Dizaynı ve Katılımcılar}

$\mathrm{Bu}$ araştırma ilişkisel tarama modelinde, tanımlayıcı bir çalışmadır. Araştırma grubunu 2018-2019 eğitim öğretim y1lında Konya'da öğrenim görmekte olan üniversite öğrencileri oluşturmaktadır. Çalışmanın verileri Kasım 2018 - Şubat 2019 tarihleri arasında toplanmıştır. Araştırmaya dahil edilme kriterlerleri; i) çalışmaya katılmaya gönüllü olmak ; ii) mevcut haliyle yeme kalitesini etkileyebilecek ruhsal veya fiziksel bir hastalığ 1 olmamak; iii) verilen ölçekleri tamamlamaya engel bir ruhsal hastalığı ya da fiziksel engeli olmamak şeklinde belirlenmiştir. İlk aşamada küme örnekleme, sonrasında uygun örnekleme yöntemi ile ulaşılan 421 üniversite öğrencisinden yüz yüze uygulama yöntemi ile veri toplanmıştır. Çalışmaya dahil edilme kriterlerine uygun olmayan 14 öğrencinin verileri kullanılmamıştır. Katılımcılara uygulanan ölçekler; araştırmacılar tarafından oluşturulmuş sosyodemografik bilgi formu, Yeme Tutumu Testi (YTT-40), Toronto Aleksitimi Ölçeği (TAÖ-20) ve Belirti Tarama Listesi (SCL-90R)'dir. Bu çalışmaya başlamak için gerekli etik kurul izni 21.03.2017 tarih ve 41901325-050.99 say1 numaras1 ile KTO Karatay Üniversitesi İlaç ve Tıbbi Cihaz Dışı Araştırmalar Etik Kurulu'ndan alınmıştır. Çalışma sürecinde Helsinki Deklarasyonunda bildirilen etik kurallara dikkat edilmiş ve katılımcılardan imzalı onam formu alınmıştır.

\section{Veri Toplama Araçları}

Sosyodemografik Bilgi Formu: Bilgi formu araştırmacılar tarafından hazırlanmıştır. Formda katılımcıların cinsiyeti, yaşı, eğitim yılı, medeni durumu, alkol ve sigara kullanımı, genel sağlık durumu ve aile öykülerine yönelik açık uçlu sorular bulunmaktadır.

Yeme Tutumu Testi (YTT-40): Ölçek anoreksiya nervoza hastaları ve sağlıklı bireylerde yeme tutumu bozukluklarını belirlemek amacıyla Garner ve Garfinkel (1979) tarafından geliştirilmiştir. Ölçek öz-bildirime dayalı 40 cümleden oluşur ve altılı likert tipindedir. Ölçeğin kesme puan 10 olarak belirlenmiştir, ölçekten 30 ve üzerinde puan alan bireylerin yeme tutumu bozuk olarak kabul edilir. Ölçeğin Türkçe geçerlilik ve güvenirlilik çalışması Savaşır ve Erol (1989) tarafından yapılmıştır. Yapplan çalışmada cronbach alfa değeri 0,70 , test - yeniden test güvenilirliği ise 0,65 bulunmuştur. Yapı geçerliği ve iç tutarlık analizleri sonucunda ölçeğin geçerli ve güvenilir bir veri toplama aracı olarak değerlendirilmesi mümkündür.

Toronto Aleksitimi Ölçeği (TAÖ-20): Ölçeğin oluşturulma amacı bireylerdeki duyguları tanıyamama olarak adlandırılan aleksitimi düzeyini belirleyebilmektir. Taylor ve arkadaşları tarafından geliştirilen ölçeğin son düzenlemesi Bagby ve arkadaşları (1994) tarafından yapılmıştır. Beşli likert formunda hazırlanan ölçek 20 maddeden oluşur ve öz-bildirime dayalıdır. Duyguları tanıma zorluğu, duyguları ifade etme zorluğu ve dişa vuruk düşünce olmak üzere 3 alt boyut içerir. Ölçeğin Türkçe geçerlilik ve güvenirlilik çalışması Güleç ve arkadaşları (2009) tarafindan yapılmıştır. Yapılan çalışmada ölçeğin kesme puanı hesaplanmamıştır. Ölçekten alınan yüksek puanlar bireylerdeki aleksitimi düzeyinin yüksekliğini göstermektedir. Yapılan çalışmada toplam ölçek için cronbach alfa değeri 0,78 , iyi uyum indeksi (GFI) bulunmuştur. Yap1 geçerliği ve uyum analizleri sonucunda ölçeğin geçerli ve güvenilir bir veri toplama aracı olarak değerlendirilmesi mümkündür.

Belirti Tarama Listesi (SCL-90-R): Ölçek ruhsal belirtilerin tespit edilmesi amaciyla Derogatis ve arkadaşları (1977) tarafından geliştirilmiştir. Likert tipinde olan ölçek 90 maddeden oluşmaktadır ve bir özbildirim ölçeğidir. Ölçek genel belirti düzeyiyle ilgili bilgi vermekle birlikte 10 belirti alt boyutunu değerlendirir. $\mathrm{Bu}$ boyutlar somatizasyon, obsesif kompulsif belirtiler, kişiler arası duyarlılık, depresyon, kayg1, düşmanlık, fobik kayg1, paranoid düşünce, psikotizm ve diğer belirtilerdir. Ölçeğin Türkçe geçerlilik ve güvenirlilik çalışması Koğar (2019) tarafından yapılmıştır. Yapılan çalışmada alt boyutlarda değişmekle birlikte alfa güvenilirlik kat sayıs1 0,72-0,89 arasında ve iç tutarlılık katsayısı yüksek bulunmuştur. Yapı geçerliği ve iç tutarlık analizleri sonucunda ölçeğin geçerli ve güvenilir bir veri toplama aracı olarak değerlendirilmesi mümkündür.

\section{İstatistik}

Verilerin değerlendirilmesi için SPSS 25.0 istatistik paket programı kullanılmıştır. Verilerin normal dağılıp dağılmadığını belirlemek için skewness ve kurtosis değerleri incelenmiş ve veri setinin analiz için uygun niteliğe sahip olduğu belirlenmiştir. Yeme bozukluğu olan ve olmayan gruplar kategorik olarak ayrılmıştır. Ölçeklerden elde edilen puanların cinsiyet değişkenine göre farklılaşıp farklılaşmadığını belirlemek için bağımsız gruplar için $t$ testi uygulanmıştır. Yeme bozukluğu ve aleksitimi arasındaki ilişkileri belirleyebilmek için Pearson Momentler Çarpımı korelasyon analizi yapılmıştır. Yeme bozukluğu olan ve olmayan kişilerde yaşam alanı, gelir düzeyi, alkol-sigara kullanımı gibi demografik değişkenlerin ve aleksitimi puanlarının farklılaşıp farklılaşmadığını belirlemek için tek yönlü varyans analizi yapılmıştır. Anlamlılık değeri $\mathrm{p}<0,05$ olarak kabul edilmiştir. 
Tablo 1.

Katılımcıların Sosyodemografik Özellikleri

\begin{tabular}{lcc}
\hline & $\begin{array}{l}\text { Sayı } \\
(\mathrm{n})\end{array}$ & $\begin{array}{l}\text { Yüzde } \\
(\%)\end{array}$ \\
\hline Cinsiyet & & \\
Kadın & 237 & 58.2 \\
Erkek & 170 & 41.8 \\
Yaş Grupları & & \\
18 - 20 & 306 & 75.18 \\
21 - 23 & 100 & 24.57 \\
24 ve üzeri & 1 & 0.25 \\
Medeni Durum & & \\
Bekar & 395 & 97.05 \\
Evli & 11 & 2.70 \\
Dul veya Boşanmış & 1 & 0.25 \\
Yaşam Alanı & & \\
Ailesi ile birlikte & 292 & 71.74 \\
Yurtta & 63 & 15.48 \\
Arkadaşı ile evde & 46 & 11.30 \\
Diğer & 6 & 1.48 \\
Gelir Düzeyi & & \\
Asgari ücretli ve altı & 73 & 17.93 \\
2500 - 5000 lira & 226 & 55.53 \\
5000 lira üzeri & 108 & 26.54 \\
Sigara Kullanımı & & \\
Var & 168 & 41.28 \\
Yok & 239 & 58.72 \\
Alkol Kullanımı & & \\
Var & 60 & 14.74 \\
Yok & 347 & 85.26 \\
\hline
\end{tabular}

Tablo 2.

Yeme Bozukluğu Durumuna Göre Aleksitimi ve Alt Ölçeklerinin Puan Ortalamaları

\begin{tabular}{lllll}
\hline & YB + & YB - & & \\
& $\mathrm{n}=85$ & $\mathrm{n}=322$ & $\mathrm{~F}$ & $\mathrm{p}$ \\
\hline Aleksitimi toplam puan & 53.48 & 50.90 & 0.594 & $\mathbf{0 . 0 1 0}^{*}$ \\
Duyguları tanıma zorluğu & 17.38 & 16.16 & 0.025 & $\mathbf{0 . 0 4 0}^{*}$ \\
Duyguları ifade etme zorluğu & 13.50 & 12.28 & 0.544 & 0.776 \\
Dişa vuruk düşünce & 22.62 & 20.34 & 1.417 & $\mathbf{0 . 0 0 1}^{*}$ \\
\hline
\end{tabular}

${ }^{*} \mathrm{p}<0.05$, YB +: Yeme Bozuklukları Olanlar, YB -: Yeme Bozuklukları Olmayanlar

\section{Tablo 3.}

Yeme Bozukluğu ile Aleksitimi Arasındaki Korelasyon Değerleri

\begin{tabular}{llclll}
\hline & YB & Aleksitimi & DTZ & DİZ & DVD \\
\hline YB & 1 & 0.127 & 0.101 & 0.014 & 0.166 \\
\hline
\end{tabular}

DİZ: Duyguları İfade Etme Zorluğu, DTZ: Duyguları Tanıma Zorluğu,

DVD: Dışa Vuruk Düşünce, YB: Yeme Bozuklukları

\section{Tablo 4.}

Yeme Bozukluğu Olanlarda Ruhsal Belirtilerin Dă̆ılımı

\begin{tabular}{lccc}
\hline & YB+ olanda belirti indeks değeri & $\mathrm{F}$ & $\mathrm{p}$ \\
\hline Depresyon & 1.11 & 0.649 & 0.199 \\
Kayg1 & 1.12 & 6.861 & $\mathbf{0 . 0 0 8}^{*}$ \\
Somatizasyon & 0.65 & 0.334 & 0.276 \\
Obsesif Kompulsif Bel. & 0.88 & 1.194 & 0.411 \\
Kişiler Arası Duyarlılık & 0.48 & 1.207 & 0.406 \\
Düşmanca Tutum & 1.34 & 0.067 & $\mathbf{0 . 0 0 7}^{*}$ \\
Fobik Kayg1 & 0.57 & 0.050 & 0.128 \\
Paranoya & 0.39 & 0.416 & 0.096 \\
Psikotizm & 0.92 & 3.003 & $\mathbf{0 . 0 2 2}^{*}$ \\
\hline${ }^{*}$ p $<0.05$, YB+: Yeme Bozukluğu Olanlar & & &
\end{tabular}

${ }^{*} \mathrm{p}<0.05, \mathrm{YB}+$ : Yeme Bozukluğu Olanlar 


\section{Sonuçlar}

Araştırmaya gönüllü katılan 421 kişiden 14 kişi ölçekleri eksik doldurduğu için çalışma dişı bırakılmıştır. Araştırma grubunu, yaş ortalaması 19,82 $\pm 10,11$ olan, 237 kadın $(\% 58,2)$ ve 170 erkek $(\% 41,8)$ oluşturmaktadır. Katılımciların \%97'si bekar, \%71,7'si ailesi ile birlikte yaşamakta ve $\% 55,5$ 'i ailesini orta gelir düzeyine sahip olarak (aylık kazançları 3000 - 5000 lira arasında) tanımlamıştır. Öğrencilerin \%41,3'ü sigara bağımlısı olduklarını, \%14,7'si alkol kullandıklarını ancak bağımlı olmadıklarını bildirmişlerdir. Katılımcıların sosyodemografik özellikleri Tablo 1'de sunulmuştur.

Çalışma sonuçlarına göre, araştırma grubundaki kişilerde yeme tutumu bozukluğu sıklı̆̆ $\% 20,9$ ve YYT-40 ölçeği puan ortalaması $22,17 \pm 14,73$ 'dür. Kadınların YYT-40 ölçeği puan ortalaması $27,67 \pm 20,72$ olup erkeklerin puan ortalamasından yüksekliği anlamlıdır $(\mathrm{p}=0,004)$. Yeme tutumu bozukluğu ile kişilerin yaşama alanı, gelir düzeyi, alkol kullanımı arasında ilişki bulunamamıştır ancak sigara içenlerde yeme tutumu bozukluğu anlamlı düzeyde yüksek saptanmıştır ( $\mathrm{p}=0,033)$.

Yeme tutumu bozuk olan kişilerde aleksitimi toplam puan ortalamas1 $53.48 \pm 10.36$ olup, yeme tutumu bozuk olmayanlara göre anlamlı düzeyde $(\mathrm{p}=0,010)$ yüksektir. Aleksitimi alt ölçeklerine göre değerlendirildiğinde, duyguları tanıma zorluğu $(p=0,040)$ ve dışa vuruk düşünce $(p=0,001)$ ölçek puanlarının YB olan bireylerde anlamlı yüksek olduğu, duyguları ifade etme alt ölçek puanının ise farklılaşmadığı görülmüştür. Yeme bozukluğu olan ve olmayan kişilerin aleksitimi toplam ve alt ölçek puan değerleri Tablo 2'de, YB ile aleksitimi arasındaki ilişki Tablo 3'de sunulmuştur.

Katılımcılar genel ruhsal belirtileri açısından değerlendirildiğinde, YB olan bireyde kaygı $(p=0,008)$, düşmanlık $(p=0,007)$ ve psikotizm $(p=0,022)$ indeks puanlarının YB olmayanlara göre anlamlı yüksek olduğu tespit edilmiştir. Depresyon indeks (di) puanı YB olan bireylerde yüksek bulunmuştur $(\mathrm{di}=1,3)$ ancak bu yükseklik istatistiksel açıdan anlaml fark oluşturmamaktadır. Yeme bozukluğu olan bireylerin ruhsal belirtilerinin indeks değerleri Tablo 4'de sunulmuştur.

\section{Tartışma}

Araştırma sonuçlarına göre, üniversite öğrencilerinde YB yaygınlığı \%20,9'dir ve yeme tutumu bozukluğu kadınlarda daha fazladır. Yeme bozukluğu genç yetişkinlerde daha sık görülen ve değişen yaşam koşulları sebebiyle görülme yaygınlığı giderek artan ruhsal bir hastalıktır. Literatürdeki YB sıklığını araştıran çalışmalarda bildirilen sonuçlar, yapılan çalışmanın yöntemi ve çalışlan yaş grubuna göre değişkenlik göstermektedir. Ülkemizde yapılan tarama çalışmalarında, YB yaygınlığının lise öğrencilerinde $\% 2,3$, yetişkinlerde \%5,3 (Vardar ve Erzengin, 2011; Semiz, Kavakçı ve Yağı, 2013), üniversite öğrencilerinde ise daha yüksek (\%6,3 - 13,7 arasında) olduğu gösterilmiştir (İlhan ve ark., 2006; Kadığlu ve Ergün, 2015; Çelik, Yoldaşcan ve Okyay, 2016). Batı ülkeleri kaynaklı çalışmalarda üniversite öğrencilerinde YB yaygınlığının \%20'lerin üzerinde olduğu (Tavolacci ve ark., 2015) ve Doğu ülkelerine göre daha s1k karşılaşıldığı bildirilmektedir (Qıan ve ark., 2013). Bu araştırmadaki oranlar, Batı ülkelerine benzer düzeyde ve ülkemizde yapılan geçmiş tarihli çalışmalara göre daha yüksek bulunmuştur. $\mathrm{Bu}$ yüksekliğin $\mathrm{YB}$ ile ilgili farkındalığın artması ve YB yaygınlığının zaman içinde artı̧̧ eğiliminde olmasıyla ilişkili olduğu düşünülmüştür. Araştırmada literatürle uyumlu olarak yeme tutumu bozukluğunun kadınlarda daha yaygın olduğu tespit edilmiştir (Andersen ve Yager, 2007).

Literatürde YB ile sigara - alkol kullanımı gibi zararlı alışkanlıklar arasındaki ilişkiyi inceleyen çalışmalar mevcuttur. Yeme bozuklukları için sigara ve alkol kullanımının her ikisi de risk olarak bildiren (Leon, Fulkerson ve Perry, 1999), her iki zararlı kullanımın YB ile ilişkisi olmadığını bildiren (Çelik ve ark., 2016), alkol kullanımının riskli olduğunu ancak sigara kullanımının YB ile ilişkili olmadığını gösteren (Özvurmaz, Mandıracıoğlu ve Lüleci, 2018) farklı çalışmalar bulunmaktadır. $\mathrm{Bu}$ araştırmanın sonuçlarında ise sigara kullanan bireylerde yeme tutumunun daha bozuk olduğu ve YB ile alkol kullanımı arasında ilişki olmadığı tespit edilmiştir. Bireysel farklılıklar göstermekle birlikte, sigara kullanımı sempatik - parasempatik uyarılmalar aracılığıyla iştah metabolizmasını bozmakta ve yeme alışkanlıklarını değiştirmektedir. Sigara içen kişilerde YB'nin daha fazla olması literatür ile uyumlu olarak değerlendirilmiştir.

Yapılan araştırmada YB ile aleksitimi arasında zayıf pozitif $(r=0,127)$ ilişki bulunmuştur. Aleksitimi alt ölçeklerine göre değerlendirildiğinde YB olan kişilerde, duyguları tanıma zorluğu ve dışa vuruk düşünce ölçek puanlarının anlamlı yüksek olduğu görülmektedir. Literatürde, bu çalıșmanın sonuçlarıyla uyumlu olarak, YB ile aleksitiminin ilişkili olduğunu bildiren araştırmalarla (Mitchell ve Mazzeo, 2005; BarrigueteMeléndez ve ark., 2019) birlikte, aralarında ilişki olmadığını tespit eden araştırmalar da bulunmaktadır (Cochrane, Brewerton ve Wilson, 1993; Çelikel, Cumurcu ve Koç, 2008). Barksky ve Klerman'a göre aleksitimik bireyler duygularına bağlı gelişen bedensel belirtilerine abartılı anlamlar yüklerler, bu sebeple bu kişilerde YB, bağımlılıklar ve dürtüsel davranışlar daha s1k görülür (Barsky ve Klerman, 1983). Duygu ve düşüncelerini ayırt edemeyen ve bunları tanıyamayan bireyler, içsel ya da dışsal uyarıları sağlıklı değerlendiremezler. Bu kişiler, hissettikleri huzursuzluğa karşı beklenmedik şekilde tepki verebilirler ve tepkileri çoğunlukla somatik şikayetler şeklindedir. Bu noktada bozulmuş yeme davranışı aleksitimik bireylerin yaşadıkları huzursuzluğa karşı geliştirdikleri bir davranış kalıbı olabilir. Sonuç olarak da aleksitimi, YB'nin oluşumunda önemli bir faktör olarak değerlendirilebilir.

Yapılan araştırmada YB olan bireylerde kaygı, düşmanca tutum ve psikotizm belirti indeksinin anlamlı yüksek olduğu, depresyon belirti indeksinin ise yüksek olmasına rağmen istatistiki anlamlılık düzeyinde olmadığı tespit edilmiştir. Yeme bozukluklarında yaşam kalitesi ve işlevselliğin belirgin bozulması, YB ile diğer ruhsal bozuklukların birlikteliği riskini arttırır. Bu alanda en çok çalışılan ruhsal hastalık depresif bozukluktur. Depresyon ile YB arasındaki ilişkinin çift yönlü olduğu tartışılmıştır; depresyonun klinik belirtileri arasında yeme tutumu değişikliklerinin olması ve YB klinik belirtileri arasında s1klıkla depresif belirtilerin varlığ her iki psikopatoloji arasındaki ilişkiyi kuvvetlendirdiği bildirilmektedir (Manaf, Saravanan ve Zuhrah, 2016). Benzer, karşıllklı 
bir ilişki de YB ile kaygı bozuklukları arasında vardır. Yeme bozukluğu olan kişilerdeki kaygı belirtileri, yeme tutumu, kilo değişimi, öğün içeriği ve kalitesi, bozulan yeme tutumuna bağlı fiziksel değişim, genel sağlık durumu, değişen kişiler arası iletişim gibi pek çok farklı içerikle ilgili olabilmektedir (Levinson ve ark., 2019). Kayg1 bozukluklarında ise stresi yönetme güçlüğü duygusal yemeye sebep olmakta ve yeme tutumunu bozabilmektedir (Matcht, 2008). Klinik özellikler açısından incelendiğinde, her iki bozukluk arasındaki ilişkinin oldukça güçlü olduğu görülmektedir. Literatürde hem yeme bozukluğu tanısı almış hastalarla yapılan çalışmalarda (Godart ve ark., 2002; Semiz ve ark., 2013) hem de klinik olmayan örneklemde yeme tutumu bozukluğu saptanan bireylerde (Çelikel ve ark., 2008) kayg1 bozukluklarının daha sik görüldüğü bildirilmektedir. Elde edilen araştırma sonuçları literatür ile uyumlu olarak değerlendirilmiştir.

Yeme bozukluğu tanısı alanlarda, alt tiplere göre değișmekle birlikte kișilik bozuklukları ve/veya uyum bozucu kişilik özellikleri birlikteliği sık görülür. T1kınırcasına yeme bozukluğu olan bireylerde dürtüsellik ve duygusal dengesizlik daha belirgin bir özellikken, kısıtlayıcı yeme bozukluğu olanlarda ise gerçeği değerlendirme yetisi bozulduğu için psikotik belirtiler daha ön plandadır. Yeme tutumu bozukluğu yaşayan kişiler duygularını düzenleyemedikleri, uygun duygulanım gösteremedikleri ve erteleyebilme becerileri yetersiz olduğu için sıklıkla diğer insanlarla çatışma içindedirler. Uyum bozucu pek çok faktöre bağlı olarak bu bireylerde sinirlilik, saldırganlık, alınganlık ve düşmanca tutumun ve psikotik belirtilerin daha s1k görüldüğ̈̈ (Truglia ve ark., 2006; Seeman, 2014) bildirilmektedir. Miootto ve arkadaşları, tıkınırcasına yeme bozukluğu olanlarda sinirlilik ve düşmanca tutumun daha sık görüldüğünü tespit etmişlerdir (Miotto, Pollini ve Restaneo, 2008). Bu çalışmada literatürle paralel biçimde, YB yaşayan bireylerde düşmanca tutum ve psikotizm puan indekslerinin anlamlı yüksek olduğu tespit edilmiştir.

Çalışmada öz-bildirime dayalı ölçeklerin kullanılması ve yeterli katılımcıya ulaşılmasına rağmen katılımcıların tek bölgeden olması kısıtlılı sebebi olarak değerlendirilebilir. Araştırmanın güçlü yanları ise; alanda çalışılan benzer örneklerle karşılaştırınca örneklem sayısının daha büyük olması, çalışılan bölgenin klinik özelliklerini temsil eden ilk çalışma olması, YB ile aleksitimik özellikler arasındaki ilişkiye dikkat çekmesidir. Sonuç olarak YB genç erişkinlerde daha sık görülen, bireysel ve toplumsal işlevselliği önemli ölçüde bozan bir psikopatolojidir. Bozuklukların erken tanınması ve tedavi edilmesi oldukça önemlidir. Psikiyatrik tedavi sürecinde prognozu etkileyebilecek diğer fiziksel ve ruhsal bozukluklar mutlaka dikkate alınmalıdır. Yeme bozuklukların etyolojisine yönelik yapılan çalışmalarda aleksitiminin de önemli bir faktör olduğuna dikkat edilmeli ve tedavide duygu odağ 1 gözden kaçırılmamalıdır. Proaktif yaklaşım açısından ise özellikle genç yetişkinlerin ruhsal sağlamlığını destekleyen ve ruhsal dayanıklılığ programların geliştirilerek uygulanması yeme bozukluklarını önleme açısından da faydalı olacaktır.

\section{Beyannameler}

\section{Beyannameler}

\section{Etik Onay ve Katılma İzni}

Bu çalışmaya başlamak için gerekli etik kurul izni 21.03.2017 tarih ve 41901325-050.99 say1 numaras1 ile KTO Karatay Üniversitesi İlaç ve Tıbbi Cihaz Dışı Araştırmalar Etik Kurulu'ndan alınmıștır. Çalışma sürecinde Helsinki Deklarasyonunda bildirilen etik kurallara dikkat edilmiş ve katılımcılardan imzalı onam formu alınmıştır.

\section{Yayın İzni \\ Uygulanamaz.}

Veri ve Materyallerin Mevcudiyeti

Mevcut çalışma sırasında kullanılan ve / veya analiz edilen veri kümeleri, makul talep üzerine ilgili yazardan temin edilebilir.

\section{Çıkar çatışmas}

Yazarlar çıkar çatışması olmadığını beyan eder.

\section{Finansman}

Uygulanamaz.

\section{Yazar Katkıları}

H.H. araştırma konusunun belirlenmesi, hipotez geliștirilmesi ve çalışma planının yapılması, literatür çalışması, verilerin toplanması, istatiksel değerlendirme, makalenin yazımı ve incelenmesi bölümlerinde görev almıştır. S.A, araştırma konusunun belirlenmesi, hipotez geliştirilmesi ve çalışma planının yapılması, literatür çalışması, verilerin toplanması, istatiksel değerlendirme, makalenin yazımı ve incelenmesi bölümlerine katkı koymuştur. Z.G.A araştırma konusunun belirlenmesi, hipotez geliştirilmesi ve çalışma planının yapılması, literatür çalışması, verilerin toplanması, istatiksel değerlendirme, makalenin yazımı ve incelenmesi bölümlerinde yer almıştır. Tüm yazarlar makalenin son halini okumuş ve onaylamıştır.

\section{Teșekkür}

Uygulanamaz.

\section{Kaynaklar}

Andersen, A.E \& Yager, J. (2007). Eating Disorders. In B.J. Sadock \& V.A. Sadock (Eds.) Kaplan\&Sadock's Comprehensive textbook of psychiatry, (pp. 2002-2022) Philadelphia: Lippincott Williams\&Wilkins.

Bagby, R.M., Taylor, G.J. ve Parker, J.D. (1994). The Twentyitem Toronto Alexithymia Scale-II. Convergent, discriminant, and concurrent validity. J Psychosom Res, 38(1), 33-40.

Barriguete-Meléndez, J.A., Pérez-Bustinzar, A., de la VegaMorales, R.I., Córdova-Villabos, J.Á., Sánchez-Gonzáles, J.M., Peón, P.B.C. ve Rojo-Moreno, L. (2019). Prevalence of alexithymia in eating disorders in a clinical sample of 800 Mexican patients. Cir Cir, 86(1), 38-43.
Barsky, A.J. ve Klerman, G.L. (1983). Overview: hypochondriasis, bodily complaints, and somatic styles. Am J Psychiatry, 140(3), 273-283.

Bayraktutan, M. (2014). Sosyal Anksiyete Bozukluğu Olan Hastalarda Empati Becerisi, Aleksitimi, Depresyon, Anksiyete Düzeyleri ile Sempatik Deri Yanıt İlişkisi ve Tıbbi Tedavinin Etkisi. (Yayınlanmamış Tipta Uzmanlık Tezi). Pamukkale Üniversitesi, Psikiyatri Anabilim Dalı, Denizli-Türkiye.

Cochrane, C.E., Brewerton, T.D., Wilson, D.B. ve Hodges, E.L. (1993). Alexithymia in the eating disorders. Int J Eat Disord, 14(2), 219-222. 
Celik, S., Yoldaşcan, E.B., Okyay, R.A. ve Özenli, Y. (2016). Kadın üniversite öğrencilerinde yeme bozukluğunun yaygınlığı ve etkileyen etkenler. Anadolu Psikiyatri Derg, 17(1), 42-50.

Celikel, F.Ç., Cumurcu, B.E., Koç, M., Etikan, İ. ve Yücel, B. (2008). Psychologic correlates of eating attitudes in Turkish female college students. Compr Psychiatry, 49(2), 188-194.

Derogatis, L.R. (1977). SCL-90: Administration, scoring and procedure manual-I for the revised version. Baltimore: John Hopkins University Press.

Duddu, V., Isaac, M.K. ve Chaturvedi, S.K. (2003). Alexithymia in somatoform and depressive disorders. J Psychosom Res, 54(5), 435-438

Garner, D.M. ve Garfinkel, P.E. (1979). The eating attitudes test: An index of the symptoms of anorexia nervosa. Psychol Med, 9(2), 273-279.

Godart, N.T., Flament, M.F., Perdereau, F. ve Jeammet, P. (2002). Comorbidity between eating disorders and anxiety disorders: A review. Int J Eat Disord, 32(3), 253-270.

Güleç, H., Köse, S., Güleç, M.Y., Çıtak, S., Evren, C., Borckardt, J. ve Sayar K. (2009). Reliability and Factorial Validity of the Turkish Version of the 20-Item Toronto Alexithymia Scale (TAS-20). Bulletin of Clinical Psychopharmacology, 19(3), 214-220.

Holtkamp, K., Muller, B., Heussen, N., Remschmidt, H. ve Herpetz-Dahlmann, B. (2005). Depression, anxiety and obsessionality in long term recovered patients with adolescentonset anorexia nervosa. Eur Child Adolesc Psychiatry, 14(2), 106-110.

İlhan, M.N., Özkan, S., Aksakal, F.N., Aslan, S., Durukan, E. ve Maral I. (2006). Bir tıp fakültesi öğrencilerinde olan yeme bozukluğu sıklığı. Türkiye'de Psikiyatri, 8(3), 151-155.

Kadıŏglu, M. ve Ergün, A. (2015). Üniversite öğrencilerinin yeme tutumu, öz-etkililik ve etkileyen faktörler. Marmara Üniversitesi Sağllk Bilimleri Enstitüsü Dergisi, 5(2), 96-104.

Kaye, W.H., Bulik, C.M., Thornton, L., Barbarich, N. ve Masters, K. (2004). Comorbidity of anxiety disorders with anorexia and bulimia nevroza. Am J Psychiatry, 161(12), 22152221.

Koğar, H. (2019). Belirti tarama listesinin (SCL-90) geçerlik ve güvenirlik çalışması: Mokken ölçekleme analizleri. Türk Psikolojik Danısma ve Rehberlik Dergisi, 9(54), 689-705.

Kountza, M., Garyfallos, G., Ploumpidis, D., Varsou, E. ve Gkiouzepas, I. (2018). The psychiatric comorbidity of anorexia nevroza: A comparative study in a population of French and Greek anorexic patients. Encephale, 44(5), 429-434.

Köroğlu, E. (2015). DSM-5 yönelimli tanısal görüşme. Ankara: HYB Yayıncilik.

Leon, G.R., Fulkerson, J.A., Perry, C.L., Keel, P.K. ve Klump, K.L. (1999). Three to four year prospective evaluation of personality and behavioral risk factors for later disordered eating in adolescent girls and boys. J Youth Adolesc, 28(2), 181-196.

Levinson, C.A., Sala, M., Murray, S., Ma, J., Rodebaugh, T.L. ve Lenze, E.J. (2019). Diagnostic, clinical, and personality correlates of food anxiety during a food exposure in patients diagnosed with an eating disorder. Eating and Weight Disorders, 24(6), 1079-1088.
Manaf, N.A., Saravanan, C. ve Zuhrah, B. (2016). The prevalence and inter-relationship of negative body image perception, depression and susceptibility to eating disorders among female medical undergraduate students. J Clin Diagn Res, 10(3), 1-4.

Matcht, M. (2008). How emotions affect eating: a five-way model. Appetite, 50(1), 1-11.

Miotto, P., Pollini, B., Restaneo, A., Favaretto, G. ve Preti, A. (2008). Aggressiveness, anger, and hostility in eating disorders. Compr Psychiatry, 49(4), 364-373.

Mitchell, K.S. ve Mazzeo, S.E. (2005). Mediators of the association between abuse and disordered eating in undergraduate men. Eating Behaviors, 6(4), 318-327.

Öztürk, O. ve Uluşahin, A. (2018). Ruh sağlığı ve bozuklukları. (15.bs). Ankara: Nobel Tip Kitabevleri.

Özvurmaz, S., Mandiracioğlu, A. ve Lüleci, E. (2018). Üniversite öğrencilerinde yeme tutumu ve yeme tutumuyla ilişkili faktörler. Adıyaman Üniversitesi Sağllk Bilimleri Dergisi, $4(2), 841-849$

Qian, J., Hu, Q., Wan, Y., L1, T., Wu, M., Ren, Z. ve Yu, D. (2013). Prevelance of eating disorders in the general population: a systematic review. Shanghai Archives of Psychiatry, 25(4), 213-222.

Ricciardelli, L.A., McCabe, M.P., Holt, K.E. ve Finemore, J.A. (2003). Biopsychosocial model for understanding body image and body change strategies among children. J Appl Dev Psychol, 24(4), 475-495.

Savasır, I. ve Erol, N. (1989). Yeme tutum testi: Anoreksiya nervoza belirtileri indeksi. Türk Psikoloji Dergisi, 7(23), 19-25.

Schulte, S.J. (2016). Predictors of binge eating in male and female youths in the United Arab Emirates. Appetite, 105(Oct1), $312-319$.

Seeman, M.V. (2014). Eating disorders and psychosis: Seven hypotheses. World J Psychiatr, 4(4), 112-119.

Semiz, M., Kavakçı, Ö., Yağız, A., Yontar, G. ve Kuğu, N. (2013). Sivas il merkezinde yeme bozukluklarının yaygınlığı ve etkileyen etkenler. Anadolu Psikiyatri Derg, 24(3), 149-157.

Sifneos, P.E. (1973). The prevalance of alexithymia characteristics in psychosomatic patients. Psychotheraphy and Psychosomatics, 22(2), 255-262

Tavolacci, M.P., Grigioni, S., Richard, L., Meyrignac, G., Dechelotte, P. ve Ladner, J. (2015). Eating disorders and associated health risks among university students. L Nutr Educ Behav, 47(5), 412-420.

Taylor, G.J. (2000). Recent developments in alexithymia theory and research. Can J Psychiatry, 45(2), 134-142.

Truglia, E., Mannucci, E., Lassi, S., Rotella, C.M., Faravelli, C. ve Ricca,V. (2006). Aggresiveness, anger and eating disorders: a review. Psychopathology, 39(2), 55-68.

Vardar, E. ve Erzengin, M. (2011). Ergenlerde yeme bozukluklarının yaygınlığı ve psikiyatrik eş tanıları iki aşamalı toplum merkezli bir çalıșma. Türk Psikiyatri Derg, 22(4), 205212. 